\title{
Association of Silicone Breast Implants, Breast Cancer and Anti-RNA Polymerase III Autoantibodies in Systemic Sclerosis: Case-Based Review
}

This article was published in the following Dove Press journal: Open Access Rheumatology: Research and Reviews

\section{Rossella De Angelis (1D) Jacopo Di Battista (iD Gianluca Smerilli $\mathbb{D}$ Edoardo Cipolletta Marco Di Carlo $\mathbb{D}$ Fausto Salaffi (D)}

Rheumatology Clinic, Department of Clinical and Molecular Sciences, Marche Polytechnic University, Jesi, Ancona, Italy

\begin{abstract}
Some case reports and small case series of patients with silicone breast implant (SBI) have reported the development of systemic sclerosis (SSc) many years later, despite conflicting evidence of this association in the literature. Recently, patients with SSc and antiRNA polymerase III antibodies positivity have been associated with previous silicone implants and/or breast cancer, showing clinical features that differ from the classic SSc, such as rapid and diffuse cutaneous involvement and scleroderma renal crisis (SRC). The specific autoimmune reaction is not yet fully understood, although knowledge in this regard is increasing. We describe a case that can support these previous observations, strengthening this association which must be taken into account. Clinicians should be aware of this new clinical entity, given the widespread use of silicone implants.

Keywords: systemic sclerosis, silicone breast implant, anti-RNA polymerase III antibodies, cancer
\end{abstract}

\section{Introduction}

Systemic sclerosis (SSc) is a complex, chronic autoimmune disease, affecting skin and various internal organs, whose pathogenesis appears to be attributable to genetic and environmental factors. ${ }^{1-5}$ It focuses on microvasculature and cells involved in synthesizing components of connective tissue, such as fibroblasts, and those responsible for innate and adaptive immune response, leading to small vessels damage and abnormal collagen overproduction. ${ }^{4}$

Exposure to various environmental factors such as polyvinyl chloride and silica has been thought to play a role in the development of the disease., ${ }^{3,6}$ Therefore, silicone breast implants (SBI) have been suggested as a cause for a range of autoimmune diseases including SSc, even if a definite relationship between the two conditions has not yet been conclusively proven, ${ }^{6-9}$ mostly due to a lack of consistent estimates and adequate adjustment for potential confounders. ${ }^{3,7}$ However, research among the literature reveals several SSc case reports following SBI. ${ }^{7,10-14}$

The SSc-related autoantibodies that are detectable with commercially available enzyme-linked immunosorbent assay kits (ELISAs) are anti-topoisomerase I (Topo-I), anti-centromere antibody (ACA) and anti-RNA polymerase III (RNAP III). ${ }^{15} \mathrm{SSc}$ patients with RNAP III positivity are thought to be associated with diffuse cutaneous involvement, renal crisis and malignancies concomitant to SSc onset, ${ }^{16}$ particularly breast cancer. ${ }^{16,17}$
Correspondence: Rossella De Angelis Rheumatology Clinic, "Carlo Urbani" Hospital, Jesi, Ancona 60035, Italy Email r.deangelis@staff.univpm.it 
More recently, a higher frequency of anti-RNAP III antibody in patients with SBI history than in patients with anti-Topo-I antibody or ACA was noted. ${ }^{15}$ Since the measurement kit of the anti-RNAP III antibody was not commercially available until recently, it is possible that the association of this antibody with SBI has not been sufficiently valued and is currently underestimated.

Herein, we report a patient who developed SSc several years after the diagnosis of breast cancer and subsequent silicone implants, found to be positive for anti-RNAP III antibodies.

\section{Case Presentation}

A 54-year-old woman was admitted to our hospital on April 2018 with a seven-month history of swelling and skin thickening of both hands and forearms (Figure 1), and arthralgia. She had no Raynaud's phenomenon (RP), digital tip ulcers, pitting scars, dysphagia, and dyspnea or sicca syndrome. Physical examination showed an afebrile patient, without synovitis or lung crackles. Her modified Rodnan's total skin thickness score (MRSS) was 12. Her history disclosed left breast intraductal comedonic-type carcinoma diagnosed in 2002 (p53 positive, estrogen receptor negative, progesterone receptor negative, erbB2 negative), TNM classification (extension, lymph node involvement and metastasis): pT1a, pN1mi, pMx. She underwent left mastectomy with lymph node resection and subsequent textured bilateral silicone breast implant (SBI). From January to April 2003, she went through chemotherapy treatment according to the FEC regimen (90) given once every three weeks for six cycles (5-fluorouracil $600 \mathrm{mg}$ ) $\mathrm{mq}$ - epirubicin $90 \mathrm{mg} / \mathrm{mq}$ - cyclophosphamide $600 \mathrm{mg} / \mathrm{mq}$ ). No rupture of SBI was demonstrated by Magnetic Resonance Imaging - MRI (last exam performed in May 2017). Last breast ultrasound assessment revealed mild signs of capsulitis

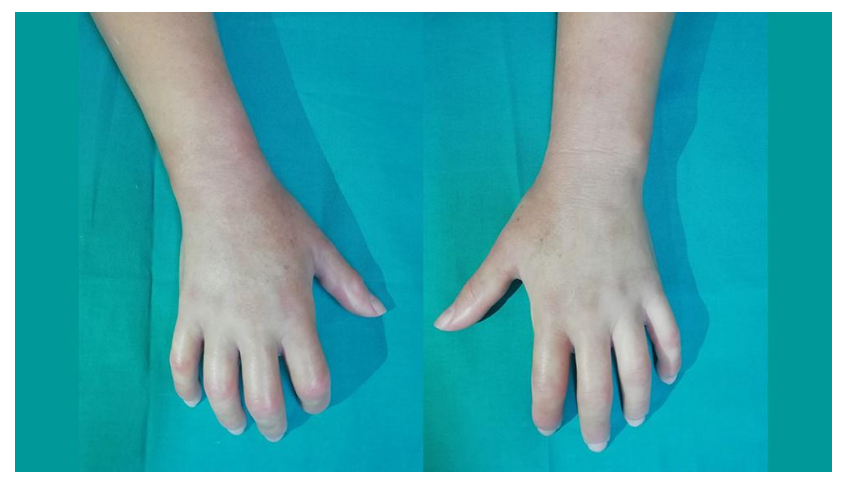

Figure I Hands' photograph of the 54-year-old woman shows thickening of the skin, flexion contractures of the interphalangeal joints and oedema. surrounding the left implant. Detailed autoantibodies analysis showed positivity of the anti-nuclear antibodies (ANA, 1:640 titer, granular pattern, indirect immunofluorescence assay) and anti-RNAP III antibodies ( $>70$ index score [normal range, 0-7], fluorescence enzyme immune assay-FEIA) but not in otheranti-extractable nuclear antigens (ENA) and anti-dsDNA antibodies. Rheumatoid factor (RF) and anti-citrullinated protein antibodies (ACPA) were negative as well. Nailfold videocapillaroscopy revealed a typical scleroderma pattern with prominent disorganization of the microvascular structure, neoangiogenesis and well detectable areas without capillaries (Figure 2). A diagnostic workup (chest high-resolution computed tomography-HRCT and abdomen ultrasound) for possible underlying neoplasm was negative. These clinical, laboratory and instrumental findings led to the diagnosis of anti-RNAP III antibody-positive SSc with exclusive skin involvement. Initially treated with low-dose prednisone (5 mg/day) and methotrexate (MTX) $10 \mathrm{mg} /$ weekly, the patient's condition rapidly worsened. Clinical evaluation showed diffuse cutaneous involvement with further centripetal progression involving the forearms, thighs and chest with no signs of pulmonary or cardiac disease. On December 2018, the patient developed severe pruritus, melanodermia and joint contractures due to skin traction. Laboratory tests showed persistence of ANA positivity (1:640 granular/nucleolar pattern, indirect immunofluorescence assay) with an increased title of anti-RNAP III ( $123 \mathrm{U} / \mathrm{mL}$, fluorescent enzyme immune assay-FEIA). No abnormal findings could be detected by chest HRCT, pulmonary function tests (PFTs) and diffusion lung CO. MTX was stopped and infusion with iloprost was started for seven days in association with mycophenolate mofetil (1.5 $\mathrm{g} /$ day). Low-dose prednisolone (10 $\mathrm{mg} /$ day) was employed for her painful edema and sclerosis. The patient experienced slowly progressive subjective improvement, with decreased pruritus, arthralgia and stiffness, and improvement of mRSS 26->20. The titer of anti-RNAP III decreased (123 ->90 IU/ $\mathrm{mL}$, fluorescent enzyme immunoassay-FEIA). ANA positivity remained (1:1280 speckled, indirect immunofluorescence assay). The provisional Composite Response Index for early diffuse cutaneous SSc (CRISS), based on the modified Rodnan skin thickness score, patient and physician global assessments and the Health Assessment Questionnaire disability index, showed that the patient had improved since the start of combination therapy with iloprost, mycophenolate mofetil and prednisone.

Patient's written consent was obtained on October 3rd, 2019, according to international ethical guidelines, for 

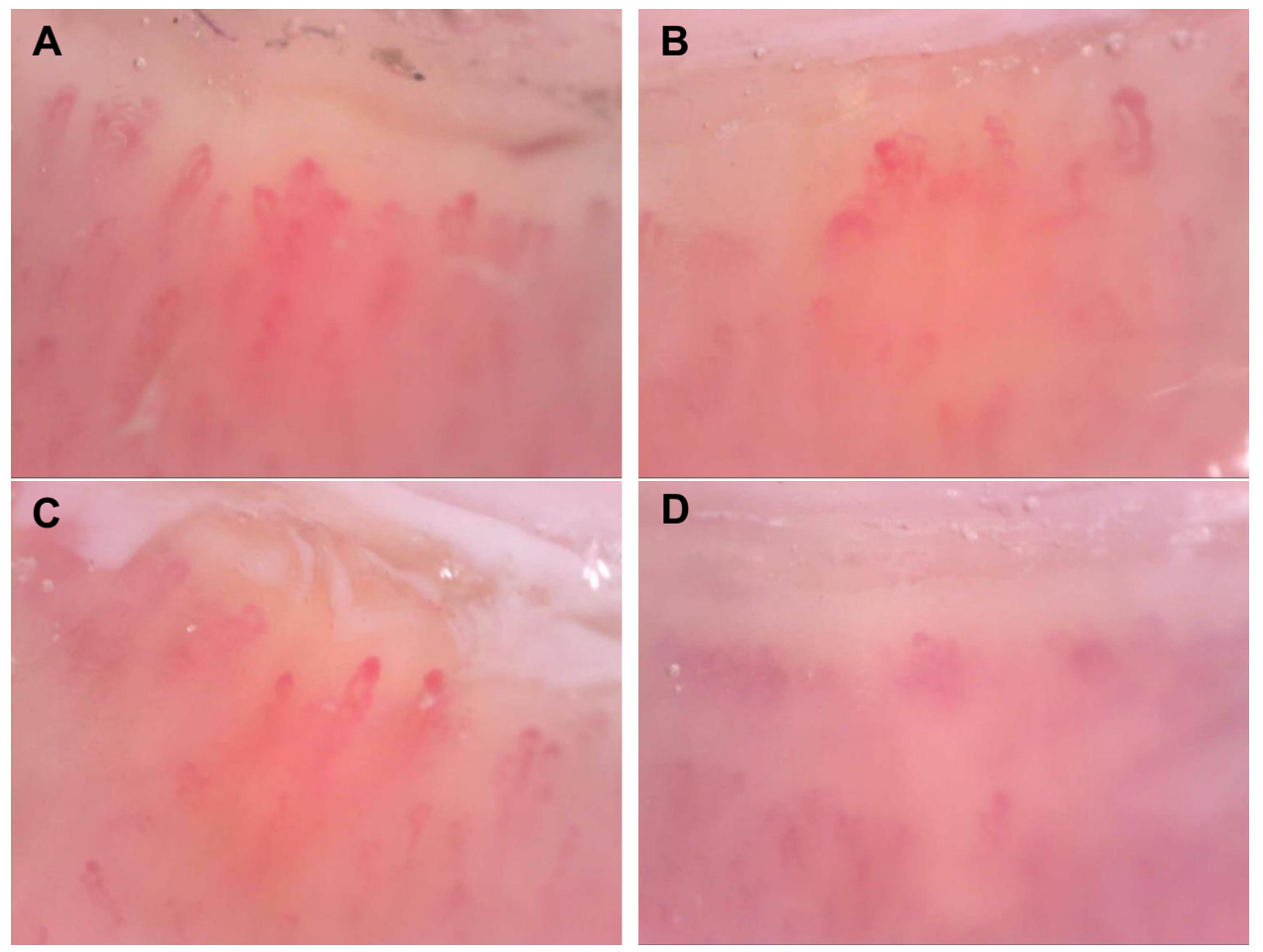

Figure 2 Nailfold capillaroscopy (200 x magnification): Capillary abnormalities revealing a "scleroderma pattern": (A and B) architectural derangement with bushing and enlarged capillaries, (C) microaneurysms and (D) loss of capillaries.

details to be used in the manuscript. Institutional approval was not required to publish.

\section{Discussion}

So far, seven cases with SSc, anti-RNAP III and SBI have been described, ${ }^{15,18-20}$ and are summarized in Table 1. All were women, mostly with diffuse disease. Two cases with scleroderma renal crisis (SRC) have been observed, one of them following SBI rupture. Two cases (including the present) have a previous history of breast cancer. The median time from implant to symptoms onset for all cases was 18.0 years. Amongst organ involvement, three-sevenths had interstitial lung disease (ILD), one gastrointestinal (GI) involvement. Other clinical manifestations were Raynaud's phenomenon (RP), pleural effusion and arthritis.

\section{Incidence and Prevalence of SSc After SBI Exposure}

In the past few decades, there has been a growing body of evidence linking SBIs to autoimmunity, although this issue has generated considerable controversy ranging from veiled criticism to substantial denial that SBIs can be associated with health-damaging outcomes. ${ }^{1,21,22}$
However, a large patient-reported study of breast implant outcomes found an increased risk of certain rare harms, including autoimmune diseases such as $\mathrm{SSc},{ }^{5}$ and a realworld analysis physician-made demonstrated a significant association between having SBI and an increased risk to be diagnosed with autoimmune/rheumatic disorders, also SSc $(\mathrm{OR}>1.5, \mathrm{p}<0.05)(2)$. In the light of these data, the debate has re-opened. ${ }^{2,5}$ It should be noted that this condition falls into the so-called "ASIA" (Autoimmune/ inflammatory Syndrome Induced by Adjuvants) syndrome, systematically described by Shoenfeld and Agmon-Levin, who proposed provisional diagnostic criteria. $^{23}$

Focusing particularly on SBI and SSc, six metaanalyses $^{3,8,9,21,24,25}$ were reported in the medical literature. Perkins et $\mathrm{al}^{24}$ included 13 epidemiology studies and provided a relative risk (RR) estimate for the possible association between SBI and CTDs. The metaanalysis summary RR was 0.76 for CTD in general (95\% confidence interval [CI]: 0.55, 1.04; homogeneity $\mathrm{p}$-value $=0.073)$ and was 0.98 for SSc (95\% CI: 0.57 , 1.64; homogeneity $\mathrm{p}=0.006$ ). Regardless of the studies aggregated in this meta-analysis, no significant increase in scleroderma risk was found. 
Hochberg et $\mathrm{al}^{25}$ limited examination to the three casecontrol studies, which specifically addressed the hypothesis relative to SSc. They found a pooled crude odds ratio of 1.07 (95\% CI: $0.60,1.89)$, and a pooled adjusted odds ratio of 1.04 ( $95 \%$ CI: $0.58,1.88)$, concluding that there is no evidence of a significant association between SBI and the development of SSc.

Wong et al, based on data from case-control studies, representing a combined database of approximately 4000 cases of connective tissue disease, found a relative risk ( $95 \%$ confidence intervals) of $0.82(0.50-1.35)$ for SSc, indicating that there was no increased risk associated with SBI. ${ }^{8}$

Whorton et al included a qualitative review of the epidemiologic studies and a quantitative summary (metaanalysis) of the case-control studies. Neither the casecontrol studies, nor the other epidemiologic data support the hypothesis that SSc is associated with or causally related to breast implants. ${ }^{9}$ Janowsky et al found no evidence of an association between breast implants in general, or silicone gel-filled breast implants specifically, and any of the individual connective tissue diseases, all definite connective-tissue diseases combined, or other autoimmune or rheumatic conditions. In particular, the relative risk for SSc was 1.01 (95\% confidence interval, 0.59 to 1.73$).{ }^{21}$ Finally, the meta-analysis of Rubio Rivas included four case-control studies overall OR 1.68 (95\% CI 1.65-1.71; $\mathrm{p}<0.001)$ and six cohort studies overall RR $2.13(95 \% \mathrm{CI}$ $0.86-5.27 ; \mathrm{p}=0.10$ ). This study, unlike the previous ones, has notably shown that a potential role of SBI inducing SSc cannot be excluded, as results achieved statistical significance when analyzing case-control studies. ${ }^{3}$

\section{Mechanisms of Autoimmune Reaction}

After being introduced in 1962, SBIs have been surgically implanted in millions of women, mainly for cosmetic purposes, with a percentage of up to about $30 \%$ used as part of breast reconstructions after mastectomy. ${ }^{26}$ Silicone implants were initially considered biologically inert, but nowadays that concept is outdated, as various siliconeinduced immunological effects have been reported., ${ }^{1,2}$ Silicone gel can migrate from the outer shell after implant failure, but, very importantly, the so-called "bleed gel", which is the migration of material through the "intact" prosthesis, has been demonstrated. ${ }^{1}$ In this view, Bekerecioglu et al looked at the capsular tissue around silicone implants in asymptomatic patients, finding significantly higher concentrations of immunoglobulins ( $\operatorname{IgG}$ and $\operatorname{IgM})$ as well as anti-silicone antibodies in tissues. ${ }^{27}$
There are various mechanisms by which SBI induce autoimmune reactions, including dysregulation of the innate as well as adaptive immunity in genetically susceptible individuals. Macrophages capable of trapping silicone-containing particles have been shown to induce the release of IL-1b, activate inflammasome and B cells, thus generating an imbalance of regulatory T-cells, response T-cells and the T-helper 17 subpopulation. ${ }^{2,28,29}$

It should be noted that the cellular immune response directed against collagen (type I and III), fibronectin and fibrinogen was found to occur more frequently and intensely in women with SBIs, ${ }^{30}$ and it should be emphasized that ANAs and a variety of other antibodies were detected in $\mathrm{SBI}$ recipients. ${ }^{31}$

Focusing on the autoimmune reaction to the RNAP III antigen, the triggering mechanisms have not yet been fully clarified. RNAP III is a cytosolic DNA sensor involved in innate immune responses, able to recognize external cytosolic dsDNA such as bacteria and viruses, and then modify it into dsRNA. Through other steps, the nuclear factor $-\mathrm{jB}$ and the response paths of interferon type I can be activated. ${ }^{32}$

Taken together, it is assumed that chronic inflammation induced by innate immune response to adjuvants could aberrantly activate RNAP III and break immune tolerance, leading to the production of autoantibody to RNAP III antigen. ${ }^{15}$ In most of the cases, supporting this idea, chronic inflammatory signs were seen in computed tomography, such as calcifications around SBI [Saigusa] or capsulitis (present case), so the evidence for a causal effect between SBI and autoimmunity is still being accumulate. ${ }^{2,4}$ Silicone adjuvant action may be enhanced after rupture, facilitating this chain of events. ${ }^{18}$

\section{Breast Cancer, SSc and RNAP III}

The incidence of breast cancer in SSc patients is extremely variable and discordant when referring to the literature data. Discrepancies are related to study methods and heterogeneity among the studied populations. ${ }^{4}$

Indeed, several case series and/or retrospective cohort studies describe a short delay between breast cancer and SSc diagnosis in a subgroup of patients., ${ }^{47,33-36}$ A significant proportion of patients (61.4\%) are diagnosed with cancer between one year before and one year after SSc diagnosis. ${ }^{34}$ In the study by Colaci et al, the median time between these two conditions was 2.5 years. ${ }^{35}$ The percentage of women with breast cancer diagnosis synchronous to the onset of SSc was found to be $6.0 \%$ (95\% 
CI 3.0-12.0) in a cohort of patients with SSc and malignancy. ${ }^{16}$

These findings might suggest common pathogenesis pathways between these two diseases, ${ }^{4,37}$ involving both the female susceptibility and the influence of the same hormonal factors. ${ }^{4}$

In general, the frequency of solid tumors in anti-RNAP III patients is higher than in controls $(\mathrm{p}=0.012)$, particularly for breast cancers $(p=0.03)(16)$.

The temporal relationship between the diagnosis of SSc with specific autoantibodies RNAP III patients and breast cancer ${ }^{17,38,39}$ is confirmed by other studies, ${ }^{36,40}$ suggesting this subtype of SSc as a paraneoplastic disease with a common underlying mechanism with cancer. ${ }^{4,16,17}$ To support the paraneoplastic genesis, a specific nucleolar expression of RNAP III was observed in the malignant cells from these patients, signifying a link between cancer-related autoantigen and autoimmune response. ${ }^{41}$ Interestingly, other authors found that the polymerase III polypeptide A (POLR3A) locus is genetically altered in six of eight patients' cancers, including breast cancers, with antibodies to RNAP III, but not in other SSc patients, bringing further hypotheses to support the close link between the two conditions. ${ }^{42}$

Therefore, due to this close temporal relationship, a malignancy screening at the time of diagnosis for antiRNAP III patients with SSc is recommended. ${ }^{16}$
Our case, together with the one described by Saigusa, ${ }^{15}$ given the late-onset of SSc with respect to the diagnosis of breast cancer, along with the absence in the literature of such long sequence, cannot be ascribed to a paraneoplastic syndrome.

\section{Clinical Characteristics}

The largest population study from the EUSTAR registry found that anti-RNAP III in SSc patients were associated in multivariable analysis with renal crisis and diffuse cutaneous involvement, ${ }^{16}$ confirming other studies about the clinical characterization of SSc with anti-RNAP III patients, which is commonly associated with rapidly progressive skin fibrosis ${ }^{43}$ and renal involvement. ${ }^{18}$ No association was found relating to RP, gastrointestinal (GI) involvement, lung fibrosis on plain radiographs and HRCT. ${ }^{16}$

In our reviewed case-series, patients did not develop RP during the clinical course of the disease, except those with SRC (Table 1). Three-eighths patients had interstitial lung disease (ILD), and two with pleural effusion. The number of cases described is limited in order to establish why only a few developed lung involvement, and it is therefore difficult to draw conclusions. Nevertheless, it is interesting to argue about SRC, which has been found to be significantly associated with the presence of anti-RNAP III in SSc in a large data-base, ${ }^{16}$ and appears to be related to rapid

Table I Summary of Literature Reported Cases of Systemic Sclerosis (SSc), Anti-RNAP and Silicone Breast Implant (SBI)

\begin{tabular}{|c|c|c|c|c|c|c|c|}
\hline Ref (), Year & Study & Age & $\begin{array}{l}\text { Skin } \\
\text { Involvement }\end{array}$ & $\begin{array}{l}\text { Time to Onset } \\
\text { (Yrs) }\end{array}$ & Side & $\begin{array}{l}\text { Cancer (Yrs to SSc } \\
\text { Onset) }\end{array}$ & More Clinical Info \\
\hline $\begin{array}{l}\text { Dall'Ara et al }{ }^{18} \text {, } \\
2011\end{array}$ & $\begin{array}{l}\text { case } \\
\text { report }\end{array}$ & 55 & diffuse & 5 & bilateral & l & SBI rupture, GI \\
\hline $\begin{array}{l}\text { Al Aranjii et al }{ }^{19} \text {, } \\
2014\end{array}$ & $\begin{array}{l}\text { case } \\
\text { report }\end{array}$ & 47 & diffuse & 9 & bilateral & l & SBI rupture, SRC \\
\hline \multirow[t]{4}{*}{$\begin{array}{l}\text { Saigusa et } \text { al }^{15} \text {, } \\
2016\end{array}$} & $\begin{array}{l}\text { cohort } \\
\text { study }\end{array}$ & 48 & diffuse & 20 & l & cervical (10) & $\begin{array}{l}\text { partial removal of SBI, } \\
\text { SC, ILD }\end{array}$ \\
\hline & & 73 & diffuse & 20 & I & \multirow[t]{3}{*}{ breast and colon ( 18$)$} & ILD, SC \\
\hline & & 31 & l & 8 & I & & \\
\hline & & 79 & I & 50 & I & & ILD, pleural \\
\hline Powell et al ${ }^{20}, 2019$ & $\begin{array}{l}\text { case } \\
\text { report }\end{array}$ & 69 & diffuse & 35 & bilateral & SRC, IR & pleural effusion \\
\hline $\begin{array}{l}\text { De Angelis, } \\
\text { present case }\end{array}$ & $\begin{array}{l}\text { case } \\
\text { report }\end{array}$ & 54 & diffuse & 16 & bilateral & breast (16) & left capsulitis \\
\hline
\end{tabular}

Abbreviations: ILD, interstitial lung disease; SRC, scleroderma renal crisis; SBI, silicone breast implant; RP, Raynaud's phenomenon; GI, gastrointestinal involvement; IR, implant replacement; SC, calcifications around silicone implant. 
disease progression. This scenario might reinforce the characterization of anti-RNAP III as markers of an SSc subset particularly prone to microangiopathic complications. ${ }^{16}$

Finally, there is no conclusive evidence of health status improvement in SSc women after replacement or removal of SBIs. ${ }^{18,44}$ It should be noted, however, that some authors observed a significant relief from systemic symptoms in approximately $75 \%$ of SBI recipients after explantation (45), but this appears to be successful when explantation is combined with immunosuppressive therapy (45). Inclusion of silicone particles from surrounding tissues could explain why explantation alone is not successful in all patients (45). On this issue, there is a need for more research.

\section{Conclusions}

So far, the relationship between SBI and SSc appearance with the above-mentioned characteristics may have been missed because: (i) RNAP III antibody testing was not commercially available until recently, and (ii) it took more than 20 years for the development of SSc after SBI in most of the described cases. Studies including subjects with at least a 10-15-year follow-up should be adequately designed in the future to avoid an underestimation of risk. ${ }^{44,45}$ As previously pointed out, SBI could influence the development of SSc in a certain subset of patients with anti-RNAP III, which seems to be a peculiar property of this antibody. ${ }^{15}$ Given the widespread use of silicone implants, along with the advance in implant technology, it is important to be aware of this clinical entity over time. ${ }^{46}$ We emphasize the recommendation to search for the autoantibody profile in each patient undergoing silicone implant surgery, to learn some of the possible prognostic factors relating to their health or pathologic status. With RNAP III antibodies, the opportunity for SBI especially for cosmetic reasons must be carefully considered.

\section{Disclosure}

The authors declare that the research was conducted in the absence of any commercial or financial relationships that could be construed as a potential conflict of interest. The authors report no conflicts of interest for this work.

\section{References}

1. Cohen Tervaert JW, Colaris MJ, van der Hulst RR. Silicone breast implants and autoimmune rheumatic diseases: myth or reality. Curr Opin Rheumatol. 2017;29:348-354. doi:10.1097/BOR.0000000000000391

2. Watad A, Rosenberg V, Tiosano S, et al. Silicone breast implants and the risk of autoimmune/rheumatic disorders: a real-world analysis. Int $J$ Epidemiol. 2018;47:1846-1854. doi:10.1093/ije/ dyy 217
3. Rubio-Rivas M, Moreno R, Corbella X. Occupational and environmental scleroderma. Systematic review and meta-analysis . Clin Rheumatol. 2017;36:569-582. doi:10.1007/s10067-016-3533-1

4. Maria ATJ, Partouche L, Goulabchand R, et al. Intriguing relationships between cancer and systemic sclerosis: role of the immune system and other contributors. Front Immunol. 2019;10(9):3112. doi:10.3389/fimmu.2018.03112

5. Coroneos CJ, Selber JC, Offodile AC 2nd, Butler CE, Clemens MW. US FDA breast implant postapproval studies: long-term outcomes in 99,993 patients. Ann Surg. 2019;269:30-36. doi:10.1097/SLA.00 00000000002990

6. Dospinescu P, Jones GT, Basu N. Environmental risk factors in systemic sclerosis. Curr Opin Rheumatol. 2013;25:179-183. doi:10.1097/BOR.0b013e32835cfc2d

7. Psarras A, Gkougkourelas I, Tselios K, Sarantopoulos A, Boura P. Systemic sclerosis and silicone breast implant: a case report and review of the literature. Case Rep Rheumatol. 2014;809629.

8. Wong O. A critical assessment of the relationship between silicone breast implants and connective tissue diseases. Regul Toxicol Pharmacol. 1996;23:74-85. doi:10.1006/rtph.1996.0011

9. Whorton D, Wong O. Scleroderma and silicone breast implants. West J Med. 1997;167:159-165.

10. Meijs J, de Vries-bouwstra JK, Cohen Tervaert JW, Hoogenberg K. A case of late-onset systemic sclerosis with ruptured silicone breast implants. Neth J Med. 2018;76:243-248.

11. Wroński J, Bonek K, Stanisławska-Biernat E. Scleroderma-like syndrome in a woman with silicone breast implants - case report and critical review of the literature. Reumatologia. 2019;57:55-58. doi:10.5114/reum.2019.83241

12. Hong C, Sangle SR, Coghlan JG, D'Cruz DP. Scleroderma and breast implants. QJM. 2015;108:569-570. doi:10.1093/qjmed/hcu156

13. Motegi S, Hattori T, Tago O, Shimizu A, Ishikawa O. Systemic sclerosis associated with silicone breast implantation. Eur J Dermatol. 2013;23:894-895. doi:10.1684/ejd.2013.2167

14. Levy Y, Rotman-Pikielny P, Ehrenfeld M, Shoenfeld Y. Silicone breast implantation-induced scleroderma: description of four patients and a critical review of the literature. Lupus. 2009;18:1226-1232. doi:10.1177/0961203309347795

15. Saigusa R, Asano Y, Nakamura K, et al. Association of anti-RNA polymerase III antibody and silicone breast implants in patients with systemic sclerosis. J Dermatol. 2016;43:808-810. doi:10.1111/13468138.13292

16. Lazzaroni MG, Cavazzana I, Colombo E, et al. Malignancies in Patients with Anti-RNA Polymerase III antibodies and systemic sclerosis: analysis of the EULAR scleroderma trials and research cohort and possible recommendations for screening. J Rheumatol. 2017:44:639-647. doi:10.3899/jrheum.160817

17. Moinzadeh P, Fonseca C, Hellmich M, et al. Association of anti-RNA polymerase III autoantibodies and cancer in scleroderma. Arthritis Res Ther. 2014;16:R53. doi:10.1186/ar4486

18. Dall'Ara F, Lazzaroni MG, Antonioli CM, Airò P. Systemic sclerosis with anti-RNA polymerase III positivity following silicone breast implant rupture: possible role of B-cell depletion and implant removal in the treatment. Rheumatol Int. 2017;37:847-851. doi:10.1007/s00296-017-3654-0

19. Al Aranji G, White D, Solanki K. Scleroderma renal crisis following silicone breast implant rupture: a case report and review of the literature. Clin Exp Rheumatol. 2017;32:262-266.

20. Powell RO, Singh A, McCormick F, King J, Houlberg K, Connor A. Normotensive scleroderma renal crisis after silicone breast implant rupture. Kidney Int. 2019;95:1520. doi:10.1016/j.kint.2018.10.014

21. Janowsky EC, Kupper LL, Hulka BS. Meta-analyses of the relation between silicone breast implants and the risk of connective-tissue diseases. $N$ Engl J Med. 2000;342:781-790. doi:10.1056/NEJM2 00003163421105 
22. Balk EM, Earley A, Avendano EA, Raman G. Long-term health outcomes in women with silicone gel breast implants: a systematic review. Ann Intern Med. 2016;164:164-175. doi:10.7326/M15-1169

23. Shoenfeld Y, Agmon-Levin N. 'ASIA' - autoimmune/inflammatory syndrome induced by adjuvants. $J$ Autoimmun. 2011;36:4-8. doi:10.1016/j.jaut.2010.07.003

24. Perkins LL, Clark BD, Klein PJ, Cook RR. A meta-analysis of breast implants and connective tissue disease. Ann Plast Surg. 1995;35:561-570. doi:10.1097/00000637-199512000-00001

25. Hochberg MC, Perlmutter DL. The association of augmentation mammoplasty with connective tissue disease, including systematic sclerosis (scleroderma): a meta-analysis. Curr Top Microbiol Immunol. 1996;210:411-417.

26. Chao AH, Garza R 3rd, Povoski SP. A Review of the Use of Silicone Implants in Breast Surgery. Expert Rev Med Devices. 2016;13:143-156. doi:10.1586/17434440.2016.1134310

27. Bekerecioglu M, Onat AM, Tercan M, et al. The association between silicone implants and both antibodies and autoimmune diseases. Clin Rheumatol. 2008;27:147-150. doi:10.1007/s10067-007-0659-1

28. Vojdani A, Campbell A, Brautbar N. Immune functional impairment in patients with clinical abnormalities and silicone breast implants. Toxicol Ind Health. 1992;8:415-429. doi:10.1177/074823379200800606

29. Colaris MJL, de Boer M, van der Hulst RR, Cohen Tervaert JW. Two hundred cases of ASIA syndrome following silicone implants: a comparative study of 30 years and a review of current literature. Immunol Res. 2017;65:120-128. doi:10.1007/s12026-016-8821-y

30. Ellis TM, Hardt NS, Campbell L, Piacentini DA, Atkinson MA. Cellular immune reactivities in women with silicone breast implants: a preliminary investigation. Ann Allergy Asthma Immunol. 1997;79:151-154. doi:10.1016/S1081-1206(10)63102-X

31. Spiera RF, Gibofsky A, Spiera H. Silicone gel filled breast implants and connective tissue disease: an overview. $J$ Rheumatol. 1994;21:239-245.

32. Ablasser A, Bauernfeind F, Hartmann G, Latz E, Fitzgerald KA, Hornung V. RIG-I-dependent sensing of poly(dA: dT) through the induction of an RNA polymerase III-transcribed RNA intermediate. Nat Immunol. 2009;10:1065-1072. doi:10.1038/ni.1779

33. Abu-Shakra M, Guillemin F, Lee P. Cancer in systemic sclerosis. Arthritis Rheum. 1993;36:460-464. doi:10.1002/art.1780360405

34. Launay D, Le Berre R, Hatron PY, et al. Association between systemic sclerosis and breast cancer: eight new cases and review of the literature. Clin Rheumatol. 2004;23:516-522. doi:10.1007/s10067-004-0940-5

35. Colaci M, Giuggioli D, Vacchi C, et al. Breast cancer in systemic sclerosis: results of a cross-linkage of an Italian Rheumatologic Center and a population-based Cancer Registry and review of the literature. Autoimmun Rev. 2014;13:132-137. doi:10.1016/j.autrev.2013.09.006
36. Saigusa R, Asano Y, Nakamura K, et al. Association of anti-RNA polymerase III antibody and malignancy in Japanese patients with systemic sclerosis. J Dermatol. 2015;42:524-527. doi:10.1111/13468138.12827

37. Shah AA, Hummers LK, Casciola-Rosen L, Visvanathan K, Rosen A, Wigley FM. Examination of autoantibody status and clinical features associated with cancer risk and cancer-associated scleroderma. Arthritis Rheumatol. 2015;67:1053-1061. doi:10.1002/art.39022

38. Xu GJ, Shah AA, Li MZ, et al. Systematic autoantigen analysis identifies a distinct subtype of scleroderma with coincident cancer. Proc Natl Acad Sci USA. 2016;113:E7526-34. doi:10.1073/ pnas. 1615990113

39. Bernal-Bello D, de Tena JG, Guillén-Del Castillo A, et al. Novel risk factors related to cancer in scleroderma. Autoimmun Rev. 2017;16:461-468. doi:10.1016/j.autrev.2017.03.012

40. Airò P, Ceribelli A, Cavazzana I, Taraborelli M, Zingarelli S, Franceschini F. Malignancies in Italian patients with systemic sclerosis positive for anti-RNA polymerase III antibodies. $J$ Rheumatol. 2011;38:1329-1334. doi:10.3899/jrheum.101144

41. Shaa AA, Rosen A, Hummers L, Wigley FM, Casciola Rosen L. Close temporal relationship between onset of cancer and scleroderma in patients with RNA polymerase I/III antibodies. Arthritis Rheum. 2010;62:2787-2795. doi:10.1002/art.27549

42. Joseph CG, Darrah E, Shaa AA, et al. Association of the autoimmune disease scleroderma with an immunologic response to cancer. Science. 2014;343:152-157. doi:10.1126/science.1246886

43. Cavazzana I, Ceribelli A, Airo P, Zingarelli S, Tincani A, Franceschini F. Anti-RNA polymerase III antibodies: a marker of systemic sclerosis with rapid onset and skin thickening progression. Autoimmunity Rev. 2009;8:580-584. doi:10.1016/j.autrev.2009.02.002

44. Lidar M, Agmon-Levin N, Langevitz P, Shoenfeld Y. Silicone and scleroderma revisited. Lupus. 2012;21:121-127. doi:10.1177/ 0961203311430703

45. De Boer de Boer M, Colaris M, van der Hulst R, Cohen Tervaert JW. Is explantation of silicone breast implants useful in patients with complaints? Immunol Res. 2017;65:25-36. doi:10.1007/s12026-016-8813-y

46. Bassetto F, Scarpa C, Vindigni V, Doria A. The periprosthetic capsule and connective tissue diseases: a piece in the puzzle of autoimmune/ autoinflammatory syndrome induced by adjuvants. Exp Biol Med (Maywood). 2012;237:1117-1122. doi:10.1258/ebm.2012.012151
Open Access Rheumatology: Research and Reviews

\section{Publish your work in this journal}

Open Access Rheumatology Research and Reviews is an international, peer-reviewed, open access journal publishing original research, reports, editorials, reviews and commentaries on all aspects of clinical and experimental rheumatology in the clinic and laboratory including the following topics: Pathology, pathophysiology of rheumatological diseases; Investigation, treatment and management of rheumatological diseases; Clinical trials and novel pharmacological approaches for the treatment of rheumatological disorders. The manuscript management system is completely online and includes a very quick and fair peer-review system, which is all easy to use. Visit http://www.dovepress.com/testimonials.php to read real quotes from published authors. 